\title{
Transpetrosal Approach for a Giant Thrombosed P2 Segment Posterior Cerebral Artery Aneurysm
}

\author{
Raisa SATO, ${ }^{1}$ Kosuke MiYaHARA, ${ }^{1}$ Tomu OKADA, ${ }^{1}$ Shin TANINO, ${ }^{1}$ \\ Yasuhiro URIU, ${ }^{1}$ Shunsuke HATAOKA, ${ }^{1}$ Yusuke TANAKA, ${ }^{1}$ \\ Noriaki SEKIGUCHI, ${ }^{1}$ Naoyuki NODA, ${ }^{1}$ Shun ISHIKAWA, ${ }^{1}$ \\ Teruo ICHIKAWA, ${ }^{1}$ and Kazuhiko FUJITSU ${ }^{1}$ \\ ${ }^{1}$ Department of Neurosurgery, National Hospital Organization Yokohama Medical Center, \\ Yokohama, Kanagawa, Japan
}

\begin{abstract}
Objective: Posterior cerebral artery (PCA) aneurysms are extremely rare and can be difficult to treat. We report successful trapping and thrombectomy of a giant thrombosed P2 segment aneurysm via a transpetrosal approach. Case Presentation: A 62-year-old woman was admitted to our hospital with a progressive left hemiparesis. Magnetic resonance imaging (MRI) showed a $30 \mathrm{~mm}$ mass lesion in the right ambient cistern. On vertebral angiography, the right P2 trunk was deviated medially and inferiorly, and the right posterior temporal artery (PTA) was not visualized. We diagnosed a giant thrombosed aneurysm of the right PTA. Surgery was performed via a right posterior transpetrosal approach. The proximal P2 was identified above the oculomotor nerve in the ambient cistern, and a giant PTA aneurysm was found. After coagulating the distal PCA, a temporary clip was applied to the proximal P2, the aneurysm wall was incised, thrombus was removed, and a permanent titanium clip was applied to complete trapping. Postoperative MRI showed disappearance of the aneurysm. The patient's left hemiparesis was resolved 2 months after the operation, and she was discharged home. Conclusion: Although trans-sylvian and subtemporal approaches are often performed for P2 aneurysms, they have difficulty identifying the distal PCA and may require excessive brain retraction. The transpetrosal approach can also be effective for giant thrombosed P2 aneurysms.
\end{abstract}

Keywords: posterior cerebral artery, giant thrombosed aneurysm, transpetrosal approach

\section{Introduction}

Posterior cerebral artery (PCA) aneurysms are extremely rare and account for $0.7 \%-2.3 \%$ of all intracranial aneurysms. ${ }^{1-5)}$ They are often difficult to treat because of their scholarly characteristics. Complete understanding of the various surgical approaches to these aneurysms is necessary to select the best treatment method. We report successful

Received June 18, 2020; Accepted January 21, 2021

Copyright $\odot 2021$ The Japan Neurosurgical Society This work is licensed under a Creative Commons AttributionNonCommercial-NoDerivatives International License. trapping and thrombectomy of a giant thrombosed P2 segment aneurysm causing brainstem compression via a transpetrosal approach.

\section{Case Report}

A 62-year-old woman with a history of breast cancer was admitted to our hospital because of a several-month history of progressive left hemiparesis, which was confirmed on neurological examination (4/5 on manual muscle testing). Magnetic resonance imaging (MRI) showed a $30 \mathrm{~mm}$ diameter mass in the right ambient cistern compressing the brainstem; the periphery of the lesion exhibited contrast enhancement, and the signal intensity within the mass suggested thrombus (Figs. 1A-1C). 

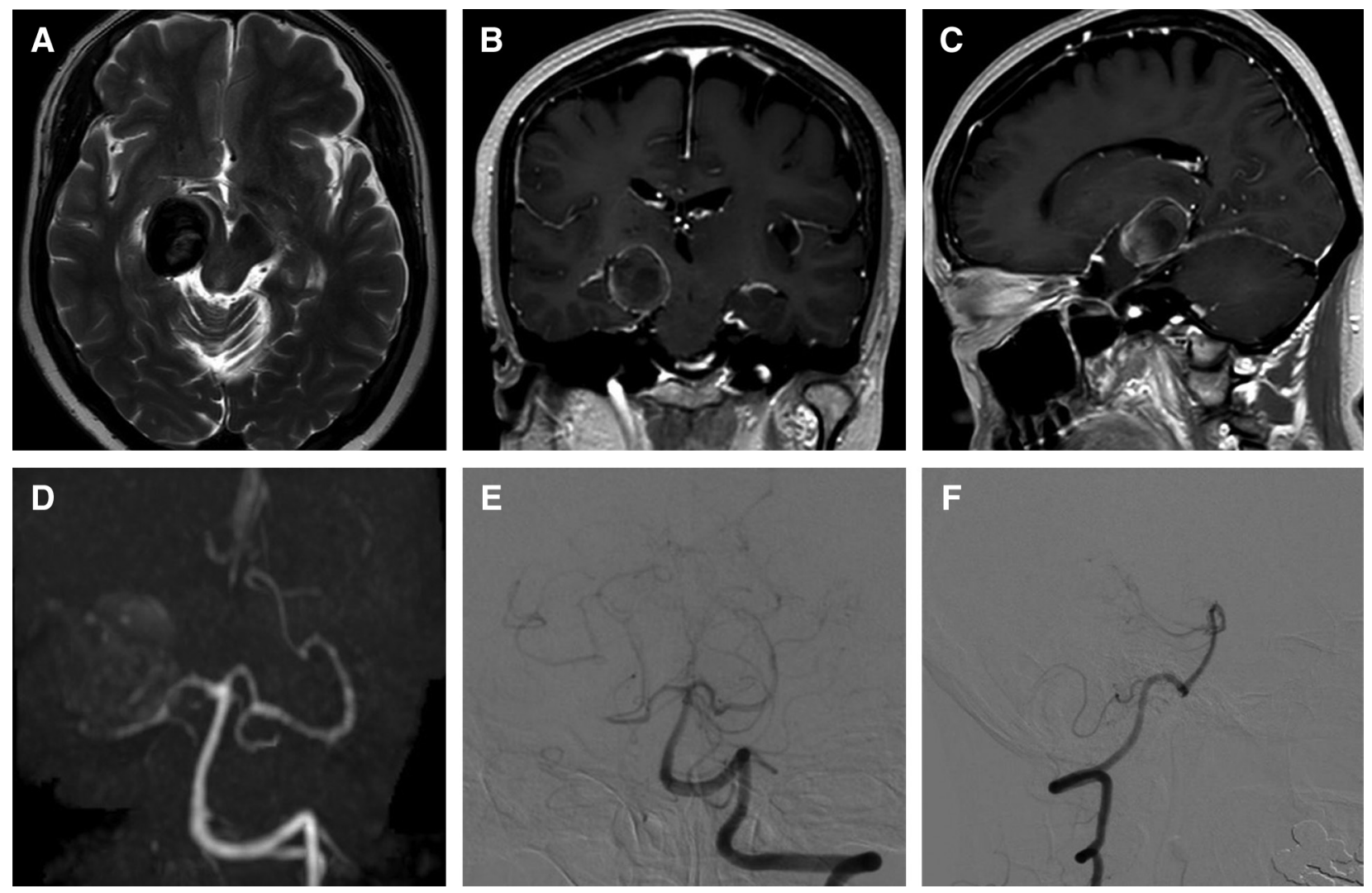

Fig. 1 (A) Axial T2-weighted magnetic resonance imaging (MRI) on admission demonstrates an extra-axial mass in the right ambient cistern causing marked compression of the right cerebral peduncle. Coronal (B) and sagittal (C) T1-weighted enhanced MRI shows homogeneous peripheral enhancement. Magnetic resonance angiography (D) demonstrates the lesion as an avascular area, and the right posterior cerebral artery is occluded distally. On anteroposterior (E) and lateral (F) left vertebral angiography, the right P2 is shifted medially and inferiorly, elongated, and tenuous; no contrast is visualized in the posterior temporal artery.

The vasculature distal to the right $\mathrm{P} 2$ segment was poorly visualized on magnetic resonance angiography (Fig. 1D). Cerebral angiography showed medial and inferior displacement of the main trunk of the right P2 segment (Figs. $1 \mathrm{E}$ and $1 \mathrm{~F}$ ). On the basis of the above, we diagnosed a giant thrombosed aneurysm of the right posterior temporal artery (PTA) and surgery is planned to relieve the brainstem compression.

To open the dura overlying the middle and posterior fossa and divide the tentorium, a petrosectomy was conducted after inserting a lumbar drain and performing a right temporo-suboccipital craniotomy in the left park bench positon. The right oculomotor nerve was identified in the ambient cistern, with the proximal P2 above. The PTA was then followed distally to reveal a completely thrombosed giant aneurysm. Before coagulating the distal PTA, the back flow from the distal side could be confirmed using temporary clip, suggesting good development of collateral blood flow. A temporary clip was applied to the proximal PTA; then, the aneurysm wall was incised, the intra-aneurysmal thrombus was removed as much as possible, and a permanent titanium clip was applied to the proximal PTA (Figs. 2A-2C). Postoperative MRI showed a shrunken residual aneurysm (Fig. 2D) and no cerebral infarction (Fig. 2E). Two months after the operation, the left hemiparesis was resolved, and she was discharged home.

\section{Discussion}

According to Zeal and Rhoton, ${ }^{6)}$ direct surgery for P2 aneurysms mainly uses the trans-sylvian or subtemporal approach. Yasargil found that most anteriorly located P2 aneurysms can be reached by the trans-sylvian approach; however, in some cases, excision of the anterior hippocampus is required after accessing it via a transinsular, transchoroidal 

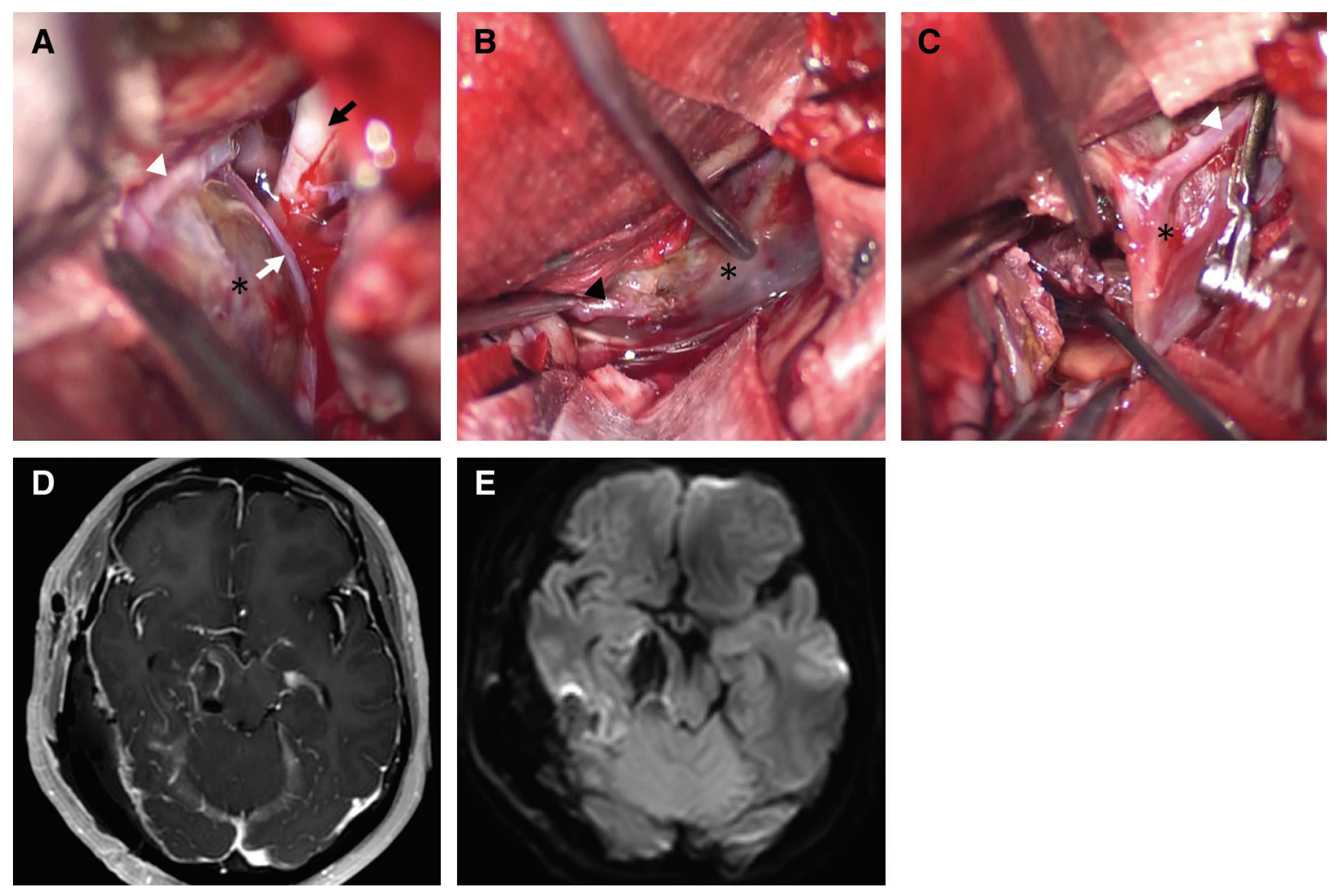

Fig. 2 Intraoperative photograph showing the view after a right posterior transpetrosal approach (asterisk: aneurysm; black arrow: oculomotor nerve; white arrow: P2 main trunk; white arrowhead: proximal posterior temporal artery (PTA); black arrowhead: distal PTA). (A) The right oculomotor nerve and proximal P2 can be seen in the ambient cistern; the giant aneurysm is located distally along the right posterior temporal artery. (B) The distal P2 is coagulated. (C) Intra-aneurysmal thrombus is excised after temporary clip placement. Postoperative contrast-enhanced axial T1-weighted magnetic resonance imaging demonstrates a shrunken residual aneurysm (D) without evidence of cerebral infarction on diffusion-weighted sequences (E).

fissure approach. ${ }^{7)}$ Anterior temporal and zygomatic approaches to P2 aneurysms have also been reported. ${ }^{8,9)}$ In 1969, Drake et al. reported the subtemporal approach in a series of eight patients with PTA bifurcation aneurysms and emphasized the satisfactory orientation of the operative field and ease of securing parent blood vessels. ${ }^{10)}$ This approach is widely used today for PCA aneurysms located from the P1 to the P3 segment. ${ }^{9,11-14)}$

Of the PCA aneurysms, $20 \%-50 \%$ are giant and thrombosed..$^{2,3,10,11,15-21)}$ To the best of our knowledge, 10 cases of direct surgery for a giant P2 aneurysm have been reported since 1980, including this case (Table 1). Most operations consisted of aneurysm trapping and proximal occlusion of the parent artery. However, if brainstem compression is present, as in this case, aneurysm thrombectomy is required. ${ }^{13)}$ The results of surgery were relatively good, which is because of the presence of good collateral circulation in the PCA territory. ${ }^{10,12,17)}$ In cases of large PCA aneurysms, the subtemporal approach may be inadequate: the PCA is displaced superiorly, and considerable temporal lobe retraction is required; moreover, visualization of the distal PCA and P3 aneurysms is difficult. ${ }^{1,4,13)}$ Similarly, it is difficult to access the distal PCA via the zygomatic approach. ${ }^{8)}$

The transpetrosal approach can be observed from the posterior petrosectomy from the retrolabyrinth presigmoid window in the shallower operative field from the posterior-inferior to the anterior-superior part without brain retraction (Fig. 3). The proximal PCA is also easily identifiable above the oculomotor nerve. ${ }^{22)}$ Craniotomy, although time-consuming, is a very useful approach through which hearing loss and cerebrospinal fluid leakage complications can be avoided. This approach should be considered for P2 segment aneurysms. 
Table 1 Reported cases of open surgical treatment for giant (>25 mm) P2 aneurysms since 1980

\begin{tabular}{|c|c|c|c|c|c|c|}
\hline No. & Authors (year) & Age/sex & Clinical features & Thrombus & Treatment approach & Result \\
\hline 1 & Fukamachi ${ }^{15)} 1982$ & $48 / \mathrm{F}$ & $\mathrm{SAH}$ & N/A & Pterional trapping & Fair \\
\hline 2 & Ohwaki $^{17)} 1986$ & $31 / \mathrm{F}$ & Headache & N/A & Subtemporal proximal clipping & Good \\
\hline 3 & Mochimatsu $^{8)} 1987$ & $36 / \mathrm{F}$ & $\mathrm{SAH}$ & $\begin{array}{l}\text { Partially } \\
\text { thrombosed }\end{array}$ & $\begin{array}{l}\text { Zygomatic clipping, } \\
\text { thrombectomy }\end{array}$ & Fair \\
\hline 4 & Seoane $^{3)} 1997$ & $41 / \mathrm{M}$ & $\mathrm{SAH}$ & $\mathrm{N} / \mathrm{A}$ & Subtemporal proximal clipping & Fair \\
\hline 5 & Seoane $^{3)} 1997$ & $54 / \mathrm{F}$ & $\mathrm{SAH}$ & N/A & Subtemporal trapping & Good \\
\hline 6 & Terasaka $^{13)} 2000$ & $47 / \mathrm{F}$ & Headache & no & $\begin{array}{l}\text { Pterional + subtemporal } \\
\text { clipping, thrombectomy + } \\
\text { STA-PCA bypass }\end{array}$ & Good \\
\hline 7 & Shimizu $^{4)} 2001$ & $42 / \mathrm{M}$ & Incidental & $\begin{array}{l}\text { Partially } \\
\text { thrombosed }\end{array}$ & Subtemporal proximal clipping & Fair \\
\hline 8 & Ture $^{21)} 2003$ & $37 / \mathrm{M}$ & Hemiparesis & Totally thrombosed & $\begin{array}{l}\text { Pterional trapping, total } \\
\text { excision of the aneurysm }\end{array}$ & Fair \\
\hline 9 & Shindo $^{19)} 2004$ & $40 / \mathrm{F}$ & $\mathrm{SAH}$ & $\begin{array}{l}\text { Partially } \\
\text { thrombosed }\end{array}$ & $\begin{array}{l}\text { Subtemporal (using circulatory } \\
\text { arrest and profound } \\
\text { hypothermia) clipping }\end{array}$ & Fair \\
\hline 10 & Present case & $62 / \mathrm{F}$ & Hemiparesis & Totally thrombosed & $\begin{array}{l}\text { Transpetrosal trapping, } \\
\text { thrombectomy }\end{array}$ & Good \\
\hline
\end{tabular}

PCA: posterior cerebral artery.

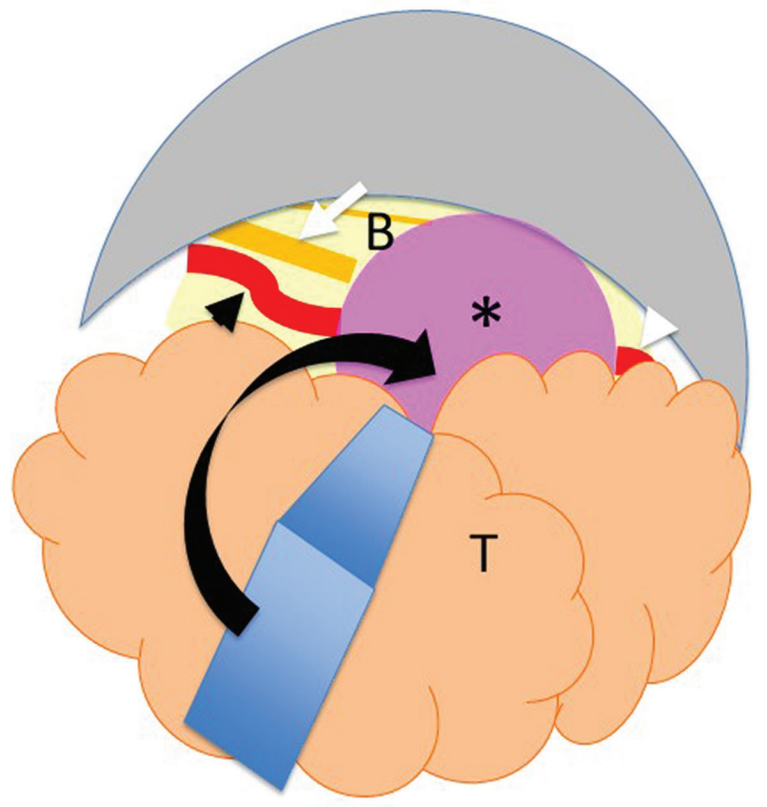

A

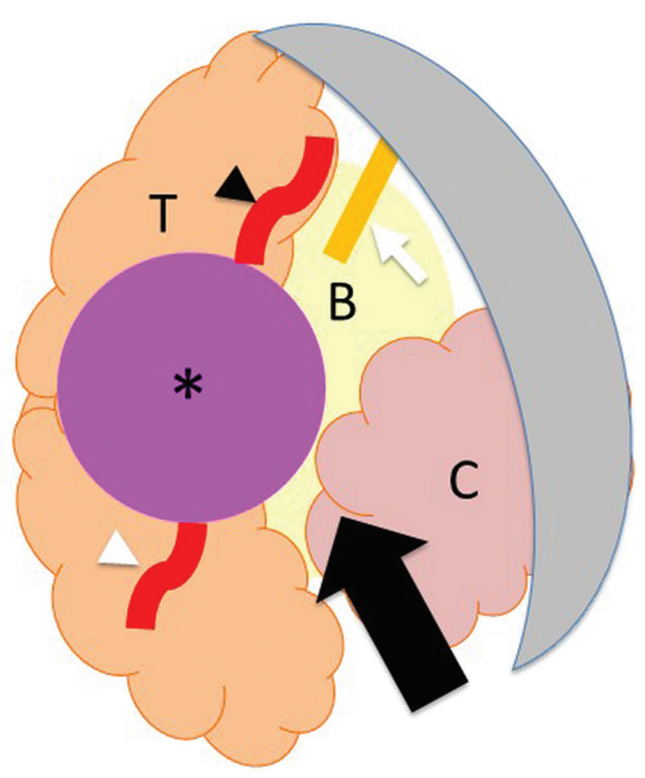

B

Fig. 3 Schematic drawing of the surgical approach in the right side. (A) subtemporal approach; (B) posterior transpetrosal approach (black arrow: approach route; asterisk: aneurysm; white arrow: oculomotor nerve; black arrowhead: proximal PCA; white arrowhead: distal PCA). B: brainstem, C: cerebellum, PCA: posterior cerebral artery, T: temporal lobe. 


\section{Conflicts of Interest Disclosure}

All the authors have no conflicts of interest.

\section{References}

1) Nishimura T, Fukuoka M, Ono Y: A case report of a distal posterior cerebral artery (P3) aneurysm, not accessible through a subtemporal approach. No Shinkei Geka 24: 1011-1014, 1996 (Japanese)

2) Sakata S, Fujii K, Matsushima T, et al.: Aneurysm of the posterior cerebral artery: report of eleven casessurgical approaches and procedures. Neurosurgery 32: 163-167; discussion 167-168, 1993

3) Seoane ER, Tedeschi H, de Oliveira E, Siqueira MG, Calderón GA, Rhoton AL: Management strategies for posterior cerebral artery aneurysms: a proposed new surgical classification. Acta Neurochir (Wien) 139: 325-331, 1997

4) Shimizu T, Manabe H, Hasegawa S, et al.: A case of posterior cerebral artery partially thrombosed giant aneurysm successfully treated by proximal occulusion. Surg Cereb Stroke 29: 290-295, 2001 (Japanese)

5) Honda M, Tsutsumi K, Yokoyama H, Yonekura M, Nagata I: Aneurysms of the posterior cerebral artery: retrospective review of surgical treatment. Neurol Med Chir (Tokyo) 44: 164-168; discussion 169, 2004

6) Zeal AA, Rhoton AL: Microsurgical anatomy of the posterior cerebral artery. J Neurosurg 48: 534-559, 1978

7) Yasargil MG: Microneurosurgery Vol II. Georg Thieme Verlag. Stuttgart/New York. 1984, pp 232-269

8) Mochimatsu Y, Fujitsu K, Hayashi A, Inada Y: Giant aneurysm of the distal posterior cerebral artery. Case report. Neurol Med Chir (Tokyo) 27: 214-217, 1987

9) Nakamura M, Miyazaki T, Shinozaki N, et al.: Surgical approaches to posterior cerebral artery aneurysms. Surg Cereb Stroke 45: 89-94, 2017 (Japanese)

10) Drake CG, Amacher AL: Aneurysms of the posterior cerebral artery. J Neurosurg 30: 468-474, 1969

11) Gi H, Uno J, Ikai Y, et al.: Seven cases of posterior cerebral artery aneurysms. No Shinkei Geka 35: 345352, 2007 (Japanese)
12) Goehre F, Lehecka M, Jahromi BR, et al.: Subtemporal approach to posterior cerebral artery aneurysms. World Neurosurg 83: 842-851, 2015

13) Terasaka S, Sawamura Y, Kamiyama H, Fukushima T: Surgical approaches for the treatment of aneurysms on the P2 segment of the posterior cerebral artery. Neurosurgery 47: 359-364; discussion 364-366, 2000

14) Uygur E, Atilla K, Levent G, Deniz B, Mustafa AS, Murad B: Subtemporal approach for a P2-P3 junction aneurysm of the posterior cerebral artery. J Clin Neurosci 14: 494-497, 2007

15) Fukamachi A, Hirato M, Wakao T, Kawafuchi J: Giant serpentine aneurysm of the posterior cerebral artery. Neurosurgery 11: 271-276, 1982

16) Lee KC, Joo JY, Lee KS, Shin YS: Recanalization of completely thrombosed giant aneurysm: case report. Surg Neurol 51: 94-98, 1999

17) Ohwaki K, Goto N, Chin M, et al.: A case of giant cerebral artery aneurysm. Jpn J Stroke 8: 120-124, 1986 (Japanese)

18) Sarica C, Tanrikulu B, Sahin Y, Dağçınar A, Baltacioglu F, Bayri Y: Acute obstructive hydrocephalus due to a giant posterior cerebral artery aneurysm in a pediatric patient. Pediatr Neurosurg 53: 247-253, 2018

19) Shindo A, Kagawa M, Kawanishi M, et al.: Three cases of thrombosed giant aneurysms of posterior cerebral artery. Surg Cereb Stroke 32: 297-301, 2004 (Japanese)

20) Taylor CL, Kopitnik TA, Samson DS, Purdy PD: Treatment and outcome in 30 patients with posterior cerebral artery aneurysms. J Neurosurg 99: 15-22, 2003

21) Türe U, Elmaci I, Ekinci G, Pamir MN: Totally thrombosed giant P2 aneurysm: a case report and review of literature. J Clin Neurosci 10: 115-120, 2003

22) Ng PY, Yeo TT: Petrosal approach for a large right posterior cerebral artery (P2) aneurysm. J Clin Neurosci 7: 445-446, 2000

Corresponding author: Kosuke Miyahara, MD Department of Neurosurgery, National Hospital Organization Yokohama Medical Center, 3-60-2 Harajuku, Totsuka-ku, Yokohama, Kanagawa 245-8575, Japan. e-mail: kosukemiyahara@outlook.jp 